\title{
What Will It Take to Increase Maternal Vaccination Rates?
}

Michelle Winokur, DrPH, and the AfPA Governmental Affairs Team, Alliance for Patient Access (AfPA)

The Alliance for Patient Access (allianceforpatientaccess.org), founded in 2006, is a national network of physicians dedicated to ensuring patient access to approved therapies and appropriate clinical care. AfPA accomplishes this mission by recruiting, training and mobilizing policy-minded physicians to be effective advocates for patient access. AfPA is organized as a non-profit 501(c)(4) corporation and headed by an independent board of directors. Its physician leadership is supported by policy advocacy management and public affairs consultants. In 2012, AfPA established the Institute for Patient Access (IfPA), a related 501(c) (3) non-profit corporation. In keeping with its mission to promote a better understanding of the benefits of the physician-patient relationship in the provision of quality healthcare, IfPA sponsors policy research and educational programming.

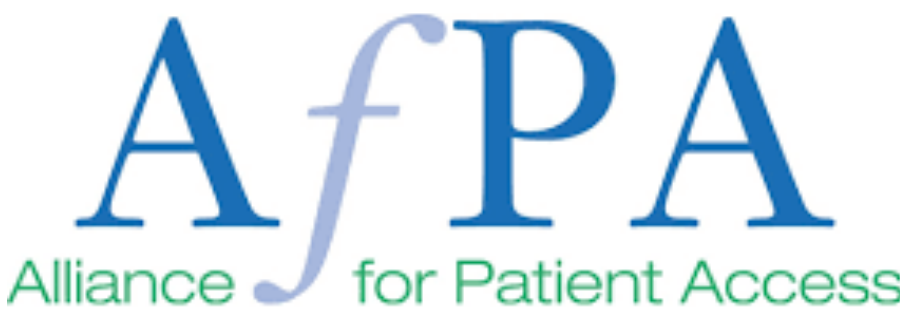

"Maternal vaccines can protect pregnant moms and vulnerable babies. So why aren't more women getting them? A new white paper, Improving Maternal Immunization Status, sheds light on this important question. (1)"

Maternal vaccines can protect pregnant moms and vulnerable babies. So why aren't more women getting them? A new white paper, Improving Maternal Immunization Status, sheds light on this important question. (1)

\section{Maternal Vaccination Challenges}

The white paper highlights two challenges related to vaccination and expectant moms.

1) Inadequate data. Determining which women experience gaps in vaccination is difficult because a comprehensive record of vaccinated pregnant women does not exist in the United States. Establishing a widely used vaccine registry or an immunization information system could help identify coverage gaps. Once armed with this information, health care professionals and policymakers could direct targeted campaigns to reach the communities with the lowest rates.

2) Poor coordination and implementation of maternal immunization programs. The people developing programs at the federal level and the health care professionals implementing those programs in the states are not communicating well with one another. Greater collaboration is necessary for overcoming on-the-ground challenges and testing solutiondriven approaches. California, for example, is piloting a program that provides clinics with Tdap starter doses so providers will have vaccines on site. This negates having pregnant women return for a subsequent appointment once the vaccine is stocked or go elsewhere to get vaccinated.

\section{"Overcoming low maternal vaccine} rates also requires education. Expectant moms may be unaware that getting these shots protects their baby during the "window of vulnerability" - before newborns can receive their own vaccinations."

\section{Educating Expectant Moms}

Overcoming low maternal vaccine rates also requires education. Expectant moms may be unaware that getting these shots protects their baby during the "window of vulnerability" - before newborns can receive their own vaccinations.

Newborns whose mothers receive both shots during pregnancy are $81 \%$ less likely to be hospitalized with flu before six months old. They are also $78 \%$ less likely to get pertussis - whooping cough - in their first two months of life, as compared to newborns whose moms did not receive the shots.

"Newborns whose mothers receive both shots during pregnancy are $81 \%$ less likely to be hospitalized with flu before six months old. They are also $78 \%$ less likely to get pertussis - whooping cough - in their first two months of life, as compared to newborns whose moms did not receive the shots." 
Despite the benefits, just $40 \%$ of expectant moms got the recommended flu and Tdap - the combination of tetanus, diphtheria, and pertussis - vaccines in 2019. Rates were even lower among Black and Hispanic expectant moms. $(2,3)$

\section{An Essential Part of Prenatal Care}

Overcoming the challenges outlined in the paper will take time and resources. But the data supporting maternal immunization vaccine recommendations are compelling, and as the authors note, the shots are "an essential part of prenatal care."

Fifteen prominent public health, professional and maternal health organizations contributed to the paper. Read more about the challenges and solutions in Improving Maternal Immunization Status.

This content article was also published at InstituteforPatientAccess.org

\section{References:}

1. https://roar-assets-auto.rbl.ms/documents/11382/Improving $\% 20$ Maternal\%20Immunization $\% 20$ Status $\% 20$ White\%20Paper\%5B2\%5D.pdf

2. https://www.cdc.gov/flu/prevent/flushot.htm

3. https://www.cdc.gov/vaccines/hcp/vis/vis-statements/tdap. $\underline{h t m l}$

Disclosures: Michelle Winokur, DrPH, is the Policy Communications Director for the Alliance for Patient Access.

\section{NT}

Corresponding Author
Michelle Winokur, DrPH,
Policy Communications Director
Alliance for Patient Access (AfPA) Government Affairs Team
1275 Pennsylvania Ave. NW, Suite 1100A Washington, DC
20004-2417
202-499-4114
Email: info@allianceforpatientaccess.org

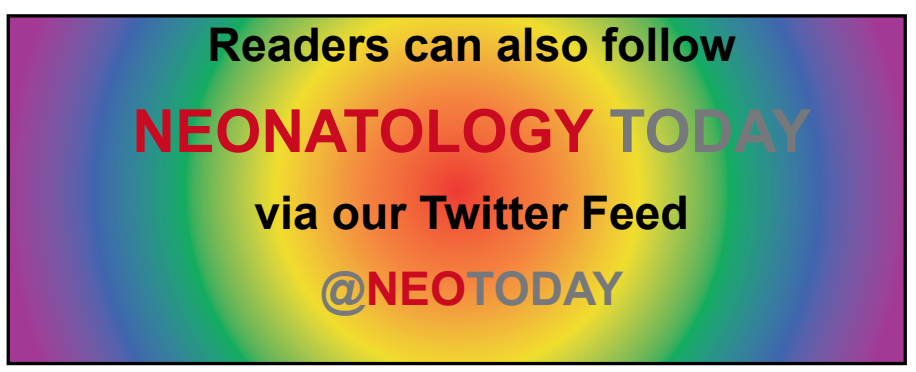

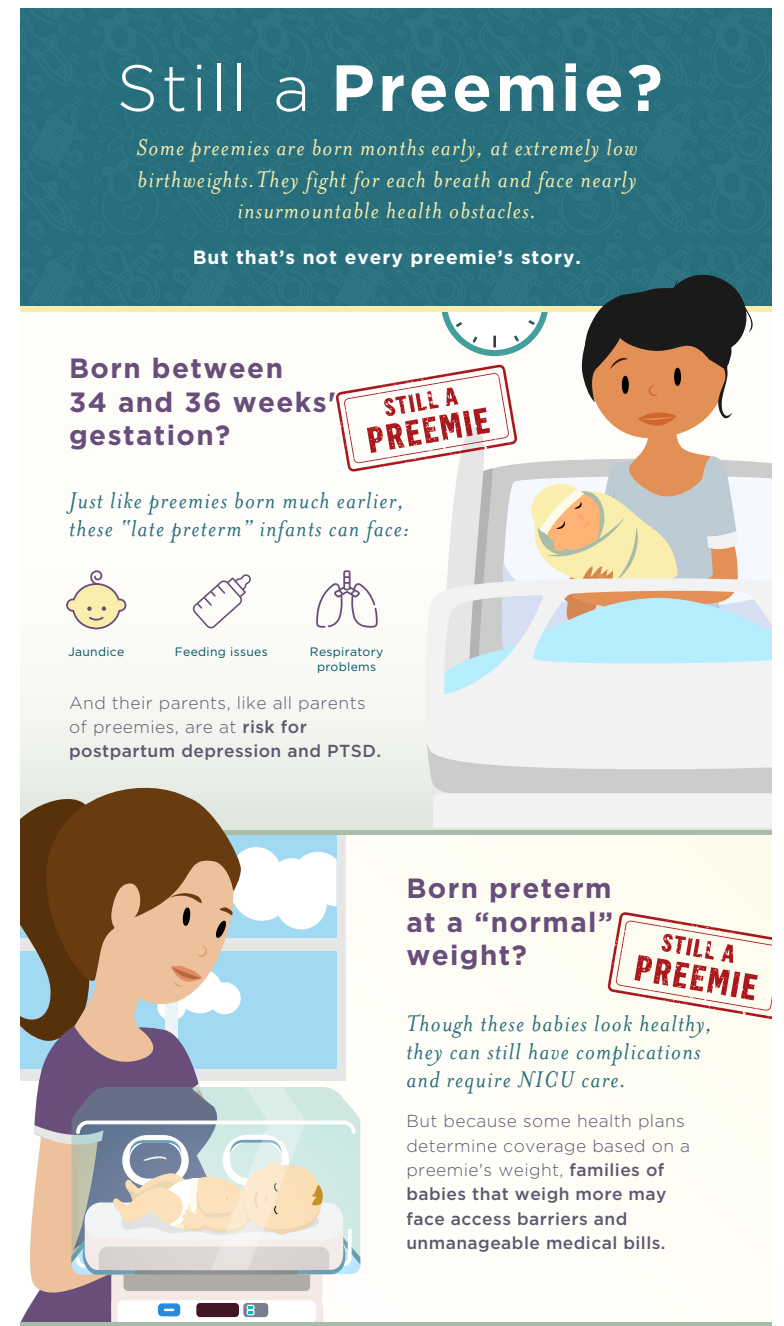

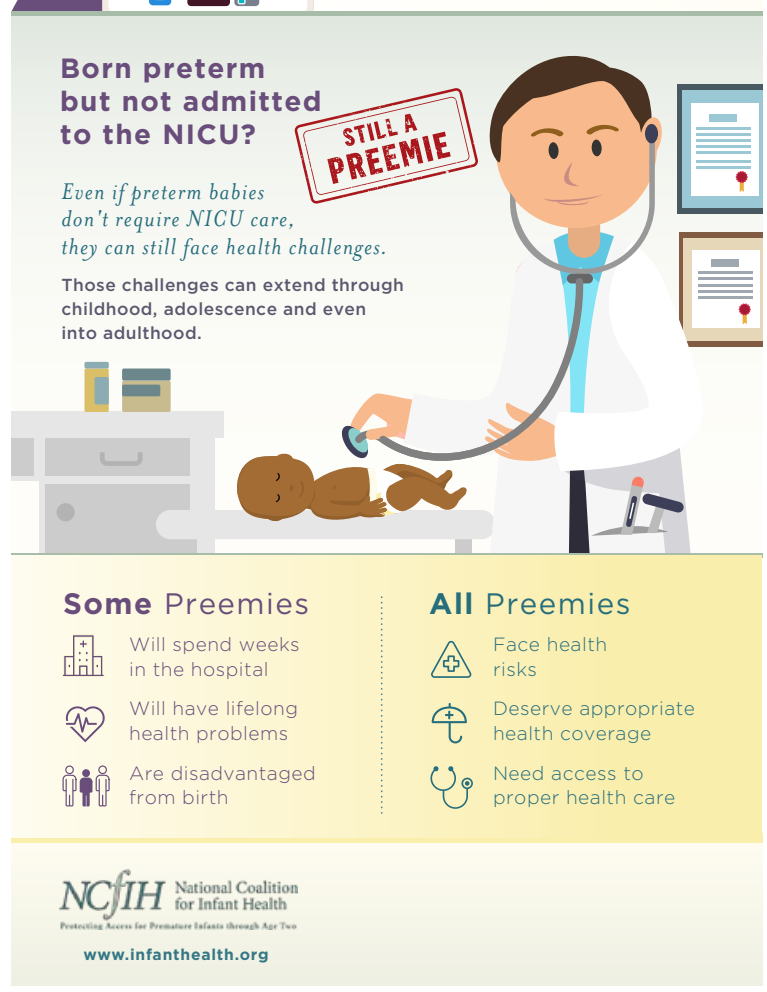

